\title{
Seroprevalance of Brucella abortus in cattle and buffaloes in district Rajanpur, Punjab, Pakistan
}

\author{
Muhammad Ismail ${ }^{1}$, Ijaz Ahmad ${ }^{1}$, Muhammad Shuaib Khan ${ }^{2}$, Shakeeb \\ Ullah $^{2}$, Muhammad Inamullah Malik ${ }^{2 *}$, Khalid Muhammad ${ }^{2}$, Kamran \\ Safder $^{2}$, Ghulam Jelani ${ }^{3}$, Assadullah Baber ${ }^{1}$ and Aftab Ahmad Jan ${ }^{4}$ \\ 1. Department of Theriogenology, University of Agriculture, Faisalabad-Pakistan \\ 2. Faculty of Veterinary and Animal Sciences, Gomal University, Dera Ismail Khan -Pakistan \\ 3. Department of Clinical Medicine and Surgery, University of Agriculture, Faisalabad-Pakistan \\ 4. Faculty of Pharmacy, Gomal University, Dera Ismail Khan-Pakistan \\ *Corresponding author's email: malikinamgu@gmail.com \\ Citation \\ Muhammad Ismail, Ijaz Ahmad, Muhammad Shuaib Khan, Shakeeb Ullah, Muhammad Inamullah Malik, Khalid \\ Muhammad, Kamran Safder, Ghulam Jelani, Assadullah Baber and Aftab Ahmad Jan. Seroprevalance of Brucella \\ abortus in cattle and buffaloes in district Rajanpur, Punjab, Pakistan. Pure and Applied Biology. Vol. 7, Issue 2, pp \\ 556-564. http://dx.doi.org/10.19045/bspab.2018.70069
}

\begin{tabular}{llll}
\hline \hline Received: 31/01/2018 & Revised: 07/04/2018 & Accepted: 14/04/2018 & Online First: 03/05/2018 \\
\hline \hline
\end{tabular}

\section{Abstract}

The current work was aimed to search out the prevalence of Brucellosis in Nili Ravi buffaloes and Dajal cattle, in tehsil Rojhan, Rajanpur and Jampur of District Rajanpur, Punjab. Animals sample size was 500 comprising of 50,50\% both buffaloes and cattle. Samples were obtained from small dairy holders and private farms. From each animal blood sample of $5 \mathrm{ml}$ was collected in a sterilized Vacutainer and centrifuged (2000 rpm for 5 minutes) for separation of serum. To determine the Brucella abortus antibodies with the help of Rose Bengal Plate Test (RBPT), plod plasma was stored at $-20^{\circ} \mathrm{C}$. The findings presented an overall prevalence of $5.2 \%(13 / 250)$ and $4.4 \%(11 / 250)$ in buffaloes and cattle, respectively $(P=0.835)$. For the animals having the history of abortion, Brucella abortus sero prevalence association was highly significant $(P<0.001)$ presenting $52.6 \%$ (buffaloes) and $38.1 \%$ (cattle). Brucellosis also showed a positive correlation with other reproductive disorders i.e. metritis, repeat breeding and Retained Fetal Membranes. For confirmation of RBPT's results, iELISA for Brucella abortus positive samples performed and results indicated an overall prevalent was 2\% (buffaloes) and1.2\% (cattle), respectively. Statistical analysis determined that the Brucella abortus's overall prevalence was non-significant in district Rajanpur, for both buffaloes and cattle.

Keywords: Brucellosis; Dajal cattle; iELISA; Nili ravi; RBPT

\section{Introduction}

Agriculture is the base of Economy in Pakistan and livestock share in Agriculture is more than half by contributing a $58.3 \%$ of total in agriculture, finally in the whole economy. Its contribution in GDP is about
776.5 billion rupees. In the country, entire population of buffaloes and cattle is 37.7 million and 44.4 million, respectively [1]. A major portion of our everyday necessities are obtained from these animals in the form of milk, meat, leather and bio-fertilizers. 
Livestock is badly affect by a large number of diseases resulting in decline of livestock's contribution in the economy and every year GDP growth of Pakistan. Brucellosis is one of the most important reproductive disorders disease that is responsible for the low infertility resulting in the decreased production rate and ultimately economic loss occur [2], causing the abortion and the endometritis [3]. World widely after rabies, it is second utmost prevalent zoonotic disease [4]. The basic bacterial species affecting the farm animals include; in goats (Brucella mellitensis), in sheep (Brucella ovis), in swines (Brucella suis) and in cattle (Brucella abortus) [2].

Birth of weak calves, the last trimester's abortion, retained fetal membrane and death of calves prepartum are major clinical signs of Brucella abortus. Aborted placenta shows grey necrotic lesions and edema. Vaginal secretions and discharge remain continue up to 2-3 months and is the major source of contamination for the water, soil and pastures. Splenomegaly, hepatomegaly, bronchopneumonia, haemorrhagic, lymph nodes swelling, fluid in thoracic cavity, may be shown in Infected fetus. Infectious conditions including of ampullae, spermatocystitis, orchitis, epididymitis, in males. Poor semen quality is observed by low motility and sperm concentration, increased morphological abnormalities and neutrophils number in semen but libido is not disturbed in affected bucks and rams [5].

Brucellosis is very important due to its zoonotic nature, can be transmitted to the employees in slaughter houses, milk man, workers, veterinarians, and persons associated with the infected animals [6]. Main sources of Brucellosis transmission included contaminated placenta, embryo, secretions of reproductive tract, contaminated utensils, water, feed and through direct or indirect interaction with infected ones. Areas where public consume infected animals' meat and milk, risk of infection is more in humans [7].

Many treatment protocols, supportive therapies, control strategies and endeavours have been used but no encouraging results [8$10]$.

Different countries have used different methodologies to control Brucellosis including vaccination, test and slaughter policy for the infected animals. It can be controlled by precautionary actions, extinguishing in animals, avoiding unhygienic, raw milk and milk's by-products. Moreover, an effective handling of milk and its products is essential for appropriate control of Brucellosis in people [11].

In Pakistan, Brucellosis prevalence is reported between the 0 to $32.5 \%$ in different studies. The Brucella' seroprevalence has been sought out in humans [12] and nearly all domestic species including horses [13] camels [14, 15], goats and sheep [16] and buffaloes and cattle, [14]. In different species Brucellosis Seroprevalence has been described as $2.14 \%$ in sheep, $9.57 \%$ in goat, $7.57 \%$ in cattle, and $8.49 \%$ in buffalo while overall in all domestic animals seroprevalence was $12.29 \%$ by RBPT and $4.58 \%$ by serum agglutination test (SAT) [17]. In 2009, Sero-prevalence of brucellosis in cattle was $24.96 \%$, in district Kohat [18] while in Pothohar region, it was $6.9 \%$ in buffaloes and $6.6 \%$ in cattle [19].

Rose Bengal Plate Test (RBPT) is considered as the best practicable in the field and most economical test for the screening of Brucella infected animals [20]. The RBPT's simple principle is the antibodies' reaction with the killed Brucella cells in the serum. PCR, ELISA and SAT can be used as confirmatory tests of RBPT positive samples [21].

No work was done in Rajanpur District and no information was available about the brucellosis prevalence in buffaloes and cattle. The recent study was aimed to determine the Brucella prevalence in Nili Ravi buffaloes 
and Dajal cattle and its relationship with various reproductive disorders.

Materials and methods

\section{Target animal population}

For this study, the animals were selected with equal share from tehsils Rojhan, Rajanpur and Jampur, district Rajanpur. A total of 500 including 250 Dajal cattle and 250 Nili Ravi buffaloes were selected from small holders and private farms. A Performa was prepared to collect the animals' reproductive history. The following formula was used for calculation of sample size with $95 \%$ C.I. $n=\frac{1.96^{2} \times P_{\exp \times\left(1-P_{\text {exp }}\right)}}{d^{2}}$

With a 5\% desired absolute precision and $20 \%$ prevalence as previous researches showed in Pakistan [18] the sample size was:

$$
n=\frac{1.96^{2} 0.20(1-0.20)}{0.05^{2}} \mathrm{n}: 246 \text { (Thrusfield, 2007) }
$$

But to be on safe side, the samples size was maintained 250 for each specie and totally 500.

\section{Collection of blood samples}

A sample of $5 \mathrm{ml}$ blood was collected in sterilized test tube from jugular vein of each animal aseptically. After collection the sample were allowed to settle down the blood till formation of clot and stored until centrifugation in refrigerator. The centrifugation was done for about $5 \mathrm{~min}$ at the rate of $2000 \mathrm{rpm}$ and separated serum was stored for further examination, at $-20^{\circ} \mathrm{C}$.

\section{Serum analysis}

\section{Sample material}

Individual Serum

\section{Statistical analysis}

The Chi-square test was used to analyse the obtained data [23]. Chi-square test was applied in specie wise sero-prevalence and correlation of seropositivity with reproductive disorders.
RBPT was used to analyse the samples serum [22] and determine the brucellosis seropositivity. For confirmation of the positive samples, indirect Enzyme Linked Immuno Sorbent Assay (iELISA) was applied.

Commercially available $\quad$ IDEXX $^{\circledR}$ Brucellosis Serum X2 test kit was used for iELISA.

\section{Calculations}

For calculations of results following formulae were applied.

Calculation of percent positivity values (PP)

All OD (optical density) values for the test samples as well as the negative control ( $\mathrm{Neg}$ C) are related to the OD values of the positive control as follows:

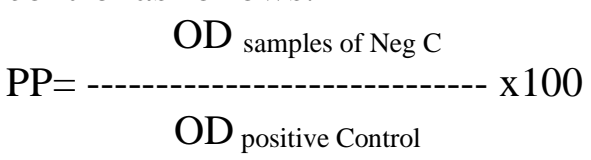

\section{Test validity criteria}

The duplicate OD values of the positive control should not differ more than $25 \%$ from the mean value of the two duplicates, to ensure validity.

Moreover; the control values should be between the following limits:

OD positive control $>.040$

OD negative control $<.040$

The test would be invalid if any of these criteria not fulfilled and technique may be suspected and the tests should be repeated.

$\begin{array}{cc}\text { OD value } & \text { Interpretation } \\ \leq \quad 0.040 & \text { Negative } \\ \geq \quad 0.040 & \text { Positive }\end{array}$

Results

In dajal cattle, Brucella abortus overall and tehsil wise prevalence by using RBPT Over all prevalence of Brucellosis for 250 animals in 3 tehsils of District Rajanpur was $4.4 \%(\mathrm{n}=11)$. The statistically analysis 
showed that in the Dajal cattle, the B.abortus prevalence was non-significant. While Tehsil wise prevalence results are as $2.4 \%(n=2)$ in Tehsil Rojhan, $3.7 \% \quad(n=3)$ in Tehsil
Rajanpur and $7.1 \%(n=6)$ in Tehsil Jampur (Table 1). Statistically analysis also revealed that the prevalence relationship among three tehsils was also non-significant.

Table 1. In Dajal cattle, overall and Tehsil wise Prevalence of B. abortus through RBPT

\begin{tabular}{|c|c|c|c|}
\hline Tehsil & N & RBPT +ve & \% age \\
\hline Overall & 250 & 11 & 4.4 \\
\hline Rojhan & 83 & 2 & 2.4 \\
\hline Rajanpur & 83 & 3 & 3.7 \\
\hline Jampur & 84 & 6 & 7.1 \\
\hline For Overall: Chi-Sq $=0.175$ & $\mathrm{DF}=1$ & $P$-Value $=0.835$ \\
For Tehsil wise: Chi-Sq $=2.448$ & $\mathrm{DF}=2$ & $P$-Value $=.294$ \\
\hline
\end{tabular}

In dajal cattle, association between abortion history and Brucella abortus by using RBPT

Out of total 250 Dajal cattle, 21 animals were having history of abortion and results showed that $38.1 \%(\mathrm{n}=8)$ were positive response for Brucella abortus. While prevalence for remaining 229 having no history of abortion was $1.3 \%(n=3)$. The statistic results showed a high significant relationship between both histories.

In dajal cattle, B. abortus overall and tehsil wise prevalence by using iELISA

The results of iELISA confirmation indicated that against brucella antibodies only $1.2 \%$ $(n=3)$ samples were positive and statistically the resulted difference was non-significant. While from 11 positive samples, only 3 showed positive results for brucella antibodies indicating, 0 samples from Tehsil Rojhan, only $1.2 \%(\mathrm{n}=1)$ in Tehsil Rajanpur and $2.3 \%(\mathrm{n}=2)$ in Tehsil Jampur by using iELISA. The resulted prevalence showed a higher percentage in tehsil Jampur than remaining two i.e. Tehsil Rojhan and Rajanpur (Table 2). Statistically, there was a non-significant relationship tehsil wise for prevalence of Brucella.

Table 2. Overall and Tehsil wise Prevalence of B.abortus in Dajal cattle through iELISA

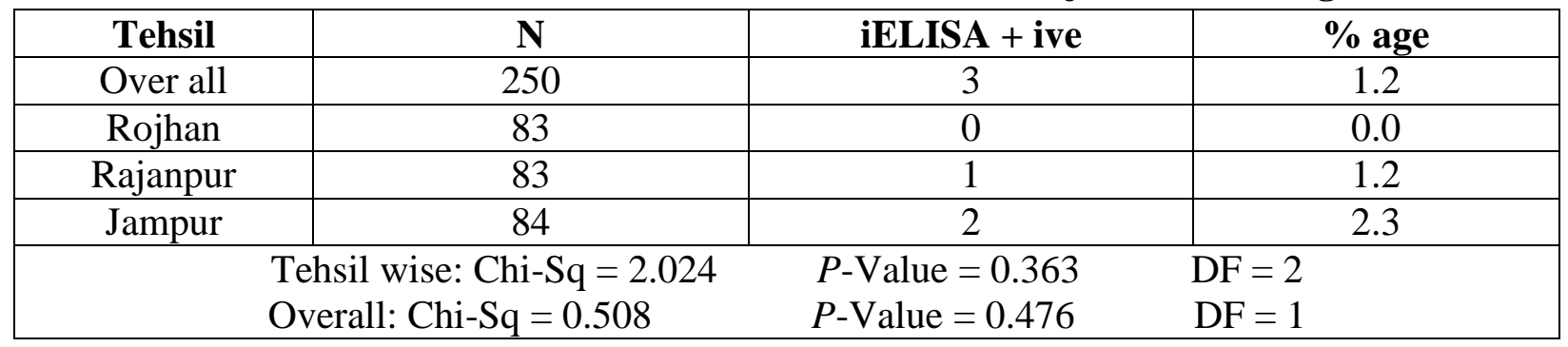

In Dajal cattle, association of Brucella abortus and abortion history by using iELISA

Out of total 250 Dajal cattle 21 animals were having history of abortion and results showed that $9.5 \%(\mathrm{n}=2)$ were positive response for Brucella abortus by using iELISA. While prevalence for remaining 229 having no history of abortion was only $0.4 \%(n=1)$. The statistic results showed a significant relationship between both histories. While statistical analysis, P-value was 0.019 showed a significant association between incidence of disease and the abortion history. 
In buffaloes B. abortus overall and tehsil wise prevalence through RBPT

Overall Brucellosis prevalence in buffaloes was $5.2 \%$ which is slightly higher than the cattle. Out of total 250 buffalo samples, only 13 showed a positive reaction as a result of RBPT. The results showed that statistically prevalence percentage was non-significant. While Tehsil wise prevalence results are as4.8\% $(\mathrm{n}=4)$ in Tehsil Rojhan, $7.2 \%(\mathrm{n}=6)$ in Tehsil Rajanpur indicating higher prevalence than other two and $3.6 \%$. In Tehsil Jampur, showed lowest prevalence than remaining both. (Table 3). Statistically analysis also revealed that the prevalence relationship among three tehsils was also non-significant.

Table 3. In buffaloes, B. abortus prevalence; overall and tehsil wise with RBPT

\begin{tabular}{|c|c|c|c|}
\hline Tehsil & $\mathbf{N}$ & RBPT +ve No. & $\%$ age \\
\hline Overall & 250 & 13 & 5.2 \\
\hline Rojhan & 83 & 4 & 4.8 \\
\hline Rajanpur & 84 & 6 & 7.2 \\
\hline Jampur & 83 & 3 & 3.6 \\
\hline & $\begin{array}{l}\text { Tehsil wise: } \mathrm{Chi}-\mathrm{Sq}=1.136 \\
\text { Overall: } \mathrm{Chi}-\mathrm{Sq}=0.175\end{array}$ & $\begin{array}{l}P \text {-Value }=0.567 \\
P \text {-Value }=0.417\end{array}$ & \\
\hline
\end{tabular}

In buffaloes, association of abortion history with seropositivity with the help of RBPT

Out of total 250 Nili Ravi Buffalo 19 animals were having history of abortion and results showed that $52.6 \% \quad(\mathrm{n}=10)$ were positive response for Brucella abortus (Table 4). While prevalence for remaining 231 having no history of abortion was $1.3 \%(\mathrm{n}=3)$. The statistic results showed a significant relationship between both histories.

Table 4. In buffaloes, association of history of abortion with seropositivity with the help of RBPT

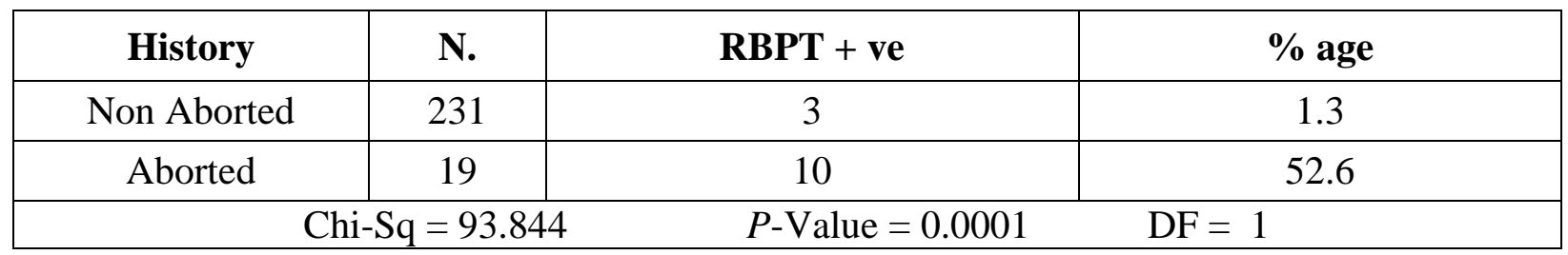

In nili ravi buffaloes, $B$. abortus overall and tehsil wise prevalence by using iELISA

The results of iELISA confirmation indicated that against brucella antibodies, only $(n=5)$ $2 \%$ samples out of 250 were positive and statistically the resulted difference was nonsignificant. While from 13 positive samples, only 5 showed positive results for brucella antibodies indicating. Tehsil wise results showed that it was equal in both Tehsil Rojhan and Jampur only $1.2 \%(\mathrm{n}=1)$ while in Tehsil Rajanpur and 3.5\% $(\mathrm{n}=3)$ in Tehsil Jampur by using iELISA. The resulted prevalence presented a greater percentage in Jampur tehsil than remaining two Tehsils: Rojhan and Rajanpur (Table 5). According to statistic, there was a non-significant relationship tehsil wise for prevalence of Brucella. 
In buffaloes, association of abortion history with seropositivity of B.abortus with the help of RBPT

Out of total 250 Nili Ravi Buffalo 19 animals were having history of abortion and results showed that $21.1 \% \quad(n=4)$ were positive response for Brucella abortus (Table 6). While prevalence for remaining 231 having no history of abortion was $0.43 \%(\mathrm{n}=1)$. The statistic results showed a significant relationship between both histories.

Table 5. In Nili Ravi buffaloes, B. abortus Overall and Tehsil wise prevalence by using iELISA

\begin{tabular}{|c|c|c|c|}
\hline Tehsil & N & iELISA +ve & \% age \\
\hline Overall & 250 & 5 & 2 \\
\hline Rojhan & 83 & 1 & 1.2 \\
\hline Rajanpur & 84 & 3 & 3.5 \\
\hline Jampur & 83 & 1 & 1.2 \\
\hline \multicolumn{2}{|c|}{ Tehsil wise: Chi-Sq $=5.533$} & $P$-Value $=0.237$ & DF $=4$ \\
& Overall: Chi-Sq $=0.508$ & $P$-Value $=0.476$ & DF $=1$ \\
\hline
\end{tabular}

Table 6. In buffaloes, association of history of abortion with seropositivity of B.abortus with the help of RBPT

\begin{tabular}{|c|c|c|c|}
\hline History & N & iELISA +ve & \% age \\
\hline Non Aborted & 231 & 1 & 0.43 \\
\hline Aborted & 19 & 4 & 21.1 \\
\hline \multicolumn{2}{|r|}{ Chi-Sq $=13.398$} & P-Value $=0.015$ & DF $=1$ \\
\hline
\end{tabular}

\section{Discussion}

All over the world brucellosis control in animals has remained a burning issue to save economy and reduce production loss. This is only possible by maintaining a disease free stock and the isolation of infected or carrier ones. The goal is only achievable with the immediate actions, sensitive and reliable diagnostic technique to diagnose the problem. Animals' screening at farm or herd level is done by serological analysis that is a sensitive and rapid tool. For that reason in this study, serological tests like iELISA and RBPT are preferred over routine bacterial isolation and identification procedure. In routine the RBPT is used to detect Brucella antibodies in sera of various species as an initial step and among different species it may have cross reaction. Therefore to confirm the results of RBPT, iELISA is applied on the positive serum samples.
According to the present study results showed that overall brucellosis prevalence in 250 Dajal cattle is $4.4 \%(n=11)$ when checked with RBPT while it was $1.2 \% \quad(n=3)$ when confirmed with iELISA. Overall Brucellosis prevalence was higher $2.3 \%$ when tested through iELISA in tehsil Jampur, for Dajal cattle which was more than other two tehsils; $(0 \%)$ in Rojhan and $(1.2 \%)$ in Rajanpur. In case of Nili Ravi buffaloes, only 5.2\% (n=13) samples were positive out of 250 samples with the help of RBPT and only 5 samples (2\%) were $B$. abortus antibodies positive when confirmed with iELISA. These results were similar to the findings by Teshale et al. [24], who reported (16\%) in Afar region that were higher than $(1.6 \%)$ in Somali region in Ethiopia. Many factors including herd size, environment conditions and farming practices may be responsible for the prevalence difference. In the present study, rate of 
brucellosis seroprevalence detected is lower than the earlier findings recorded at various Private and Government dairy farms in Pakistan. Brucella abortus was found $7.92 \%$ in cattle positive with the help of RBPT, [25]. In crossbred cattle Brucella abortus percentage was much higher at various farms in Punjab, results indicated that $27.86 \%$ with i-ELISA and $28.90 \%$ with RBPT [26]. Brucella abortus, seropositive for buffaloes and cattle was found as $7 \%$ and $14 \%$, respectively [27], which are somewhat higher than ours. The environmental factors, husbandry, vaccine quality and geographic locations may affect the severity and prevalence. Ahmad et al. [28], also concluded that due to good hygiene and ventilation, in small house holds the Brucellosis seroprevalance was less. The results of present study are also closer to [29] in Punjab, which showed an overall brucellosis prevalence $5.06 \%$ in cattle and $7.74 \%$ in buffaloes through RBPT. In Baluchistan, Quetta city, [30] results supported our study, they detected prevalence was $4.6 \%$ in cattle and $1.7 \%$ in buffaloes with the help of MRT. Disease seroprevalence is also dependent on the different factors i.e. farming system, parity number, housing conditions and age.

In the present study relationship of the abortion and disease was also inspected as earlier work in Faisalabad, Pakistan [26] and in Uttar Pradesh, India [31]. The results showed that the prevalence was lower in nonaborted animals than having the history of abortion. Same results were found [32], A positive association was also reported [33, 34]. Dairy cattle having history of abortion for $B$. abortus about $68.1 \%$ antibodies was observed [35]. Animals having abortion history were 3.89 times more probably to be seroprevalence positive than non-aborted ones, [36]. Approximately brucellosis seropositivity is associated with $35 \%$ in cattle and $20 \%$ in small ruminants' abortions, [37].
Though in the current work, brucellosis prevalence in cattle and buffalo and its association with many reproductive disorders has been considered to a large level, but it is appealing to further investigate the disease in other species including camels, goats and sheep to find out the Brucella abortus prevalence. Most of the developed countries have been eradicated this disease following test and slaughter policy which is impossible to follow in our country because of limited recourses. Therefore, some important measures are recommended for control of the Brucellosis viz; Public education, controlled personnel/ animals access, quarantine measures for new addition, improved management to avoid contamination by proper hygiene and disposal of aborted foetuses, eliminating Brucella positive reactors and appropriate milk sterilization before consumption.

\section{Conclusions}

Present study results determined that in the Rajanpur district, the Brucella abortus prevalence in buffaloes and cattle is fairly low but appropriate measures should be taken to control the economic losses in the form of increased calving interval lower milk yield and abortions.

The current study was planned to search out the Brucella abortus seroprevalence in buffaloes and cattle in Rajanpur district. Buffaloes and cattle have a basic contribution in the economy of Pakistan. These animals in the form of meat and milk contributes a large share in GDP. In year 2016-17 the whole population of buffaloes and cattle was 37.7 million and 44.4 million, respectively. They also provided a large part of our routine necessities in the form of by products, bio fertilizers and leather.

The current study was planned to search out the Brucella abortus seroprevalence in buffaloes and cattle in Rajanpur district and to identify the relationship of brucellosis with different reproductive disorders. The target 
animals were Nili Ravi buffalo and Dajal cattle of which home tract is the district Rajanpur. The samples collected were 250 from each specie, totally 500. Centrifugation was done to separate the serum and then Rose Bengal Plate Test (RBPT) was used for serum analysis and positive samples were subjected through iELISA for further confirmation.

The findings indicated an overall Brucella abortus seroprevalence as $5.2 \%$ for buffaloes and $4.4 \%$ for cattle through RBPT. The iELISA results was slightly changed than RBPT, indicating prevalence as $1.2 \%$ in cattle and $2 \%$ in Buffalo. In cattle, the results showed a higher Brucella abortus prevalence in Tehsil Jampur than other the Rajanpur and Rojhan tehsil. When data was statistically analysed a significant relationship $(P<0.05)$ was found between Brucella abortus prevalence and aborted animals.

\section{Authors' contributions}

Conceived and designed the experiments: $\mathrm{M}$ Ismail, I Ahmad \& MI Malik, Performed the experiments: M Ismail, A Baber \& G Jelani, Analyzed the data: M Ismail, S Ullah \& AA Jan, Contributed materials/ analysis/ tools: K Muhammad \& K Safder, Wrote the paper: M Ismail, MS Khan \& MI Malik.

\section{References}

1. Anonymous (2016-17). Ecomic Survey of Pakistan, Economic Advisors Wing, Finance Division, Government of Pakistan, Islamabad, Pakistan.

2. Radostits OM, Gay CC, Blood DC \& Hinchcliff KW (2000). Veterinary Medicine, $9^{\text {th }}$ Ed. W.B. Saunders Company, London, UK.

3. Berman DT (1981). Diseases of the Cattle in the Tropics. Ristic, M and Mclntyre, I. (eds) Martinus Nijhoff Pub, New York, USA.

4. Schelling E, Diguimbaye C, Daoud S, Nicolet J, Boerlin P, Tanner M \& Zinsstag J (2003). Brucellosis and Q-fever seroprevalences of nomadic pastoralists and their livestock in Chad. Prev Vet Med 61: 279-293.

5. Jane M, Mathias LA \& Robles CA (2010). Clinical manifestations of Brucellosis in domestic animals and humans. The open Vet Sci J 4: 119-126.

6. Nimri LF (2003). Diagonosis of recent and relapsed cases of human brucellosis by PCR assay. Infect Dis 28:3-5.

7. Abu-shaqra QM (2000). Epidemiological aspects of brucellosis in Jordan. Eur $J$ Epidemiol 16: 581-584.

8. Dumaresq JA (1940). Effect of sulfanilamide on Brucella abortus infection in guinea pigs and cows. Aust vet $J$ 16: 102-107.

9. Schuhardt VT, Rich GC \& Beal GA (1945). Sulfadiazine therapy in bovine brucellosis. $J$ Bact 50: 127-131.

10. Bermand DT, Irwin MR \& Beach BA (1946). The effect of penicillin on cows infected with Brucella abortus. Cornell Vet 36: 311-313.

11. Abubakar M, Mansoor M \& Arshed MJ (2011). Bovine brucellosis: old and new concepts with Pakistan perspective. Pak Vet J 32: 1-9.

12. Mukhtar F \& Kokab F (2008). Brucella serology in abattoir workers. J Ayub Med College Abbottabad 20: 57-61.

13. Gul ST, Khan A, Ahmad M \& Hussain I (2013). Seroprevalence of Brucellosis and associated hemato-biochemical changes in Pakistani horses. Pak J Agri Sci 50: 447-452.

14. Asif M, Awan AR, Babar ME, Ali A, Firyal S \& Khan QM (2009). Development of genetic marker for molecular detection of Brucella abortus. Pak J Zoo 9: 267-271.

15. Nasrin M, Afzal H \& Siddique M (1998). Sero-prevalence of Brucella abortus and Brucella melitensis in camels. J Anim Plant Sci 8: 61-62.

16. Iqbal Z, Jamil H, Qureshi ZI, Saqib M, Lodhi LA, Waqas MS \& Safdar M (2013). Seroprevalence of Ovine Brucellosis by Modified Rose Bengal Test and ELISA in Southern Punjab, Pakistan. Pak Vet J 33(4): 455-457.

17. Gul ST, Khan A, Rizvi F \& Hussain I (2014). Sero-Prevalence of Brucellosis in Food Animals in the Punjab, Pakistan. Pak Vet $J$ 34(4): 454-458.

18. Hamidullah M, Khan R \& Khan I (2009). Sero-prevalence of brucellosis in animals in district kohat NWFP and comparison of two serological tests. Pak J Sci 61(4): 242-243. 
19. Ali S, Ali Q, Abatih EN, Ullah N, Muhammad A, Khan I \& Akhter S (2013). Sero-prevalence of Brucella abortus among dairy cattle and buffaloes in Pothohar Plateau, Pakistan. Pak J Zool 45(4): 1041-1046.

20. Ruiz- Mesa JD, Gonzalez JS, Rrgyera JM, Martin L, Palmero SL \& Colmenero JD (2005). Rose Bengal Test: Diagnostic yield and use for the rapid diagnosis of human brucellosis in emergency departments in endemic areas. Clin Microbiol Infect 11: 221225.

21. Munoz PM, Marin CM, Morreal D, Gonzales, Bastuji BG \& Diaz R (2005). Efficacy of several serological tests and antigens for diagnosis of bovine brucellosis in the presence of false- positive serological results due to Yersinia enterocolitica. Clin Diag Lab Immunol 12: 141-151.

22. Brown EN (1974). An adaption of the Rose Bengal test for the diagnosis of brucellosis at abattoirs. Aust Vet J 50: 127.

23. Steel RGD, Torrie JH \& Dieky DA (1997). Principles and Procedures of Statistics. 3rd Ed., McGraw Hill Book Company, New York, USA.

24. Teshale S, Muhie $Y$ \& Kidanemariam A (2006). Seroprevalence of small ruminant brucellosis in selected districts of Afar and Somali pastoral areas of eastern Ethiopia: the impact of husbandry practice. Rev Med Vet 157: 557-563

25. Nawaz M (2011). Sero-prevalence of brucellosis and its relationship with reproductive disorders in large ruminants. M.Phil. thesis of Department of Theriogenology, University of Agriculture Faisalabad, Pakistan.

26. Ullah Q (2013). Seroprevalence of brucellosis and its relationship with reproductive disorders in cross bred cattle in different private dairy farms of Punjab province. M.Phil. thesis of Department of Theriogenology, University of Agriculture Faisalabad, Pakistan.

27. Nasir AA, Parveen Z, Shah MA \& Rashid M (2004). Seroprevalence of brucellosis in animals at government and private livestock farms in Punjab. Pak Vet J 24: 144-146.
28. Ahmad R, Munir MA \& Latecl M (1994). Production systems and brucellosis in buffaloes. Pak J Agric Sci 31: 341-344.

29. Abubakar M, Arshed MJ, Hussain M, Ehtisham-ul-Haq \& Ali Q (2010). Serological evidence of brucella abortus prevalence in Punjab province, Pakistan-a cross-sectional study. Transbound Emerg Dis 57(6): 443447.

30. Shafee M, Rabbani M, Sheikh AA, Ahmad MD \& Razzaq A (2011). Prevalence of bovine brucellosis in organized dairy farms, using milk ELISA, in Quetta city, Baluchistan, Pakistan. Vet Med Int 1-3.

31. Jain U, Bist B, Shazad, Pragati \& Dwivedi K (2012). Outbreaks of brucellosis in buffaloes aborted in village Mahuan, district Mainpuri, UP, India- A case report Vet World 6(1): 5152.

32. Safdar M (2013). Seroprevalence of caprine brucellosis in Distt. Muzzafar Garh Punjab Pakistan. M.Phil. Thesis of Department of Theriogenology, University of Agriculture Faisalabad, Pakistan

33. Ahmad MA, Talafhal AQ \& Ababneh MM (2009). Seroprevalence and risk factors for bovine brucellosis in Jordan. $J$ Vet Sci 10(1): 61-65.

34. Muma JB, Samui KL, Siamudaaia VM, Oloya J, Matope G, Omer MK, Munyeme M, Mubita C \& Skjerve E (2006). Prevalence of antibodies to brucella spp. and individual risk factors of infection in traditional cattle, goats and sheep reared in livestock-wildlife interface areas of Zambia. Tropic Anim Health Prod 38: 195-206.

35. Genc O, Otlu S \& Sahin M (2005). Seroprevalence of brucellosis and leptospirosis in aborted dairy cows. Turkish $J$ Vet Ani Sci 29: 359-366.

36. Dhand NK, Gumber S, Singh BB, Aradhana, Bal MS, Kumar H, Sharama DR, Singh J \& Sandhu KS (2005). A study on the epidemiology of brucellosis in Punjab (India) using survey toolbox. Rev Sci Tech off Int Epiz 24: 879-885.

37. Darwesh M \& Benkirane A (2001). Field investigation of brucellosis in cattle and small ruminants in Syria, 1990-1996. Rev Sci Tech off Int Epiz 3: 769-775. 